\title{
RESENHAS
}

\section{VERDADE E INTERPRETAÇÃO: UMA ABORDAGEM PAREYSONIANA SOBRE QUESTÕES FILOSÓFICAS ATUAIS}

PAREYSON, L. Verdade e Interpretação. Tradução de Maria Helena Nery Garcez e Sandra Neves Abdo. São Paulo: Martins Fontes, 2005.

Renata Gabriel de Oliveira* rgabrielo@yahoo.com.br

A publicação brasileira de Verdade e Interpretação vem trazer ao leitor, que não possui familiaridade com a língua italiana, a atualidade dos temas abordados por Luigi Pareyson (1918-1991), pelo fato da obra em questão tratar de algumas das problemáticas atuais vividas pela filosofia, ouso dizer, algumas das mais relevantes, tais como a possibilidade do discurso filosófico, o seu objeto e a sua função. É, portanto, compreensível que Verdade e Interpretação seja considerada por muitos como uma obra fundamental de Pareyson, visto que nesta ele propõe princípios fundamentais da ontologia hermenêutica contemporânea.

Este livro constitui-se como uma coletânea de ensaios publicados entre 1965 e 1970, justificando, assim, possíveis repetições que, longe de serem negativas, conservam a peculiaridade do discurso pareysoniano, cultivando o seu aspecto didático e favorecendo a compreensão de seu pensamento através de uma argumentação clara e precisa.

* Mestranda em Filosofia pela Universidade Federal de Minas Gerais

KRITERION, Belo Horizonte, nº 113, Jun/2006, p. 185-190. 
No que diz respeito à estrutura desenvolvida em Verdade e Interpretação, convém esclarecer que, mesmo sendo escritos recolhidos no decorrer de seis anos, os textos, quer pela unidade relativa aos argumentos, quer pela continuidade de seu método, podem ser concebidos como capítulos de um livro. Os assuntos abordados possuem a vantagem de ser uma tomada de posição do autor relativamente à situação moderna, ao mesmo tempo em que surgem como um trabalho que deve ser ainda desenvolvido.

A partir de uma abordagem ontológica-hermenêutica, Pareyson reivindica a necessidade e autonomia da filosofia frente à ciência, à religião e à política, defendendo sua necessidade e restituindo seu princípio fundamental, a verdade, esquecido no interior de uma tendência histórica e pragmática, técnica e instrumental, empírica e ideológica, pois suprimir o conceito de verdade é negar a própria filosofia e teorizar o seu próprio fim, algo que tem se tornado muito presente na contemporaneidade, e que tem suas raízes na filosofia moderna.

Para alcançar tal objetivo, Pareyson retoma sua filosofia da interpretação desenvolvida principalmente no seu pensamento estético, particularmente, em obras da década de 50, como Unitá della filosofia e Estética: teoria della formativitá. Verdade e Interpretação é, portanto, uma obra que ao levantar a questão da verdade e do ser, o faz através da interpretação, presente em todo operar humano, seja ele intelectual, político, artístico ou moral.

O livro divide-se em três partes que pretendem fornecer uma abordagem geral das relações entre "Verdade e História", "Verdade e Ideologia", e "Verdade e Filosofia", a partir da análise de alguns aspectos eleitos pelo autor como centrais no interior de cada relação.

Entretanto, antes de adentrar a estas questões, no "Prefácio", Pareyson esclarece alguns pontos de sua postura fundamentalmente hermenêutica, a saber, que a verdade não deve ser compreendida em sentido objetivo ou meta-histórico, por não ser objeto do pensamento, mas sua origem. E, mais importante, que a verdade não se oferece a não ser no interior de uma interpretação que, sendo pessoal e, portanto, histórica, é capaz de formulá-la sem exauri-la.

Concebida nestes moldes, a verdade pode restituir ao pensamento seu caráter revelativo hoje tão negligenciado no interior de um historicismo exacerbado, o que viria a constituir a própria sobrevivência da filosofia. Mas isso não quer dizer que Pareyson, ao defender sua posição, esteja negando toda filosofia ocidental, condenando o discurso filosófico ao silêncio, como ele afirma ter feito Heidegger. Frente à inefabilidade heideggeriana, ele defende a inexauribilidade da verdade que, inseparável do aspecto pessoalista de seu pensamento, constitui uma nova forma de afirmar a relação ontológica. 
Pareyson propõe a existência de uma solidariedade originária entre pessoa e verdade, e nesta consistiria a essência da interpretação. A relação ontológica é, antes de qualquer coisa, uma relação hermenêutica, que possibilita ao homem colocar-se frente à verdade e ao ser através da interpretação presente em todas as ações humanas. Isto porque a pessoa, para Pareyson, é ativa e receptiva, ao mesmo tempo, o que quer dizer que todo ato humano é marcado por atos interpretativos que dialogam com aquilo que é interpretado. Através da interpretação, a pessoa pode possuir a verdade, mas não definitivamente, porque esta sempre poderá ser tocada por novos pontos de vista.

Partindo do conceito de verdade e sua via de acesso, a interpretação, o autor nos apresenta na introdução - "Introdução: Pensamento expressivo e pensamento revelativo" - a idéia central deste livro, qual seja, estabelecer a distinção entre pensamento expressivo e pensamento revelativo, a fim de restituir ao pensamento "sua originária função veritativa contra a instrumentalização a que o submetem o tecnicismo e o ideologismo atuais” (p. 5).

Em relação à distinção entre pensamento revelativo e expressivo, Pareyson critica aquele tipo de discurso que, mesmo objetivando ser uma manifestação da verdade, não consegue ser outra coisa senão a expressão do tempo do qual ele faz parte, de modo que esvaziado de verdade e exprimindo somente um tempo determinado, está fadado a desaparecer com ele. Contudo, não quer negar uma consideração historicista frente à especulativa, mas sim afirmar a indissociabilidade destes dois aspectos, na medida em que devem coexistir no interior do pensamento que possui caráter revelativo. Diferentemente do pensamento expressivo, que é destituído de verdade, o pensamento revelativo será sempre e, ao mesmo tempo, expressivo, porque a verdade só se manifesta através da interpretação pessoal e esta sempre será, simultaneamente, revelação da verdade e expressão da pessoa que interpreta.

Cabe ressaltar que, como tal impasse diz respeito a toda atividade humana, caberá ao homem escolher "entre identificar-se com a própria situação ou dela fazer um trâmite para atingir a origem, entre renunciar à verdade ou dar uma revelação irrepetível dela" (p. 9). O que significa que o homem poderá ser mero produto histórico ou perspectiva vivente sobre a verdade, bem como o pensamento ser mera expressão do tempo ou revelação pessoal da verdade.

Este caminho trilhado pelo autor é imprescindível para a compreensão do todo da obra, pois somente a partir desta distinção é que podemos confrontar o discurso filosófico com o discurso meramente histórico e ideológico e estabelecer as relações fundamentais entre filosofia e verdade, de modo a percorrer toda a argumentação desenvolvida por Pareyson em Verdade e Interpretação. 
De posse das considerações acerca do conceito de verdade e de seu papel fundamental na conservação do aspecto revelativo de todo ato interpretativo, poderei realizar uma sucinta exposição dos tópicos trabalhados pelo autor nas partes constitutivas da obra, na medida em que os pontos que serão abordados encontram-se fundamentados nesta reflexão principal já mencionada.

Na primeira parte do livro, intitulada "Verdade e História", Pareyson propõe um estudo referente aos valores (Capítulo I) e ao caráter de originariedade da interpretação (Capítulo II).

No que diz respeito ao seu "Estudo sobre os Valores" (Capítulo I), o autor, diante da questão da historicidade dos valores e da durabilidade histórica, conclui que a permanência diz respeito a uma presença mais originária e profunda, sendo as formas históricas manifestações desta presença do ser. Deste modo, a durabilidade das formas históricas seria garantida através de uma relação de equilíbrio entre a exemplaridade e congenialidade. A forma histórica, enquanto exemplar, exerceria seu papel se acolhida por uma comunidade congenial, podendo, assim, agir como estímulo para uma nova atividade que congenialmente queira adotá-la. A manutenção deste equilíbrio entre conservação e inovação é, portanto, responsável pela instituição de traços duradouros na história humana.

Nossa tarefa não é, pois, distinguir, na história, o que é permanente (suprahistórico) do que é meramente temporal, visto que no que se refere à história, tudo é igualmente histórico e temporal. A questão é sabermos reconhecer nela as manifestações do ser, distinguindo-as daquilo que é somente histórico e expressivo, isto é, esvaziado de verdade.

No Capítulo II, "Originariedade da interpretação", Pareyson retoma a relação entre ser e interpretação da verdade, enfatizando que a situação pessoal é o único veículo que nos permite recuperar sua originária abertura ontológica. A pessoa, de posse de todas as suas características fundamentais, torna-se órgão revelador, multiplicando, assim, as formulações da verdade, no ato mesmo em que a mantém única, visto que a verdade é única e intemporal mesmo frente às suas múltiplas formulações. Esta unicidade, longe de impedir a infinidade interpretativa, é estímulo e alimento para todas elas, porque a verdade é uma origem inexaurível que solicita a cada vez uma nova interpretação que possa colhê-la toda sem esgotá-la, sendo sempre um convite a novas formulações.

A segunda parte da obra, "Verdade e Ideologia", possui dois capítulos, a saber, "Filosofia e ideologia" (Capítulo I) e "Destino da Ideologia" (Capítulo II), nos quais Pareyson, partindo da distinção entre pensamento expressivo e pensamento revelativo, busca enquadrar a ideologia no âmbito 
discursivo meramente histórico e expressivo, diferenciando-a do discurso filosófico que tem como fundamento a revelação da verdade. De acordo com o seu ponto de vista, a ideologia , enquanto arraigada na situação da qual emerge, promove uma historicização do pensamento e, consequentemente, tecniciza a razão, ao testemunhar uma falsa consciência e uma falsificação de seu tempo.

Deste modo mesmo que ideologia e filosofia partam da Weltanschauung, por conciliar os aspectos teórico e prático, em sua originariedade, a filosofia constitui-se como uma forma de pensamento radicado na verdade e no ser. Em contrapartida, a ideologia por negligenciar o aspecto especulativo do pensamento não consegue ser mais do que produto histórico.

Em "Verdade e Filosofia", terceira e última parte do livro, o autor finaliza sua exposição com os capítulos "Necessidade da filosofia" (Capítulo I) e "Filosofia e senso comum" (Capítulo II). No primeiro capítulo, Pareyson aborda as relações da filosofia com a ciência, a religião, a arte e a política, defendo a posição de que a primeira deve estabelecer seus limites frente às demais, tendo em vista a garantia de sua própria sobrevivência, pois não afirmar a sua peculiaridade é afirmar o seu fim: seja através da invasão da filosofia em relação aos demais âmbitos, seja por permitir que estes assumam a sua função. É imprescindível, então, que o discurso filosófico não negligencie o seu caráter especulativo em detrimento de uma postura instrumental; bem como não renuncie à verdade, diante da postura auto-reflexiva que tende a fazer da filosofia o seu próprio objetivo, descuidando do aspecto ontológico que fundamenta sua especificidade.

Finalizando, em "Filosofia e senso comum", Pareyson propõe a distinção entre estes dois âmbitos, ressaltando a contradição que acompanha o senso comum, ao oscilar entre a exigência de universalidade e sua destinada historicidade, características de um pensamento que se propõe revelativo, mas não consegue ser mais do que expressão de seu tempo. No que diz respeito ao discurso filosófico, esta característica historicidade não impede que o caráter de universalidade da filosofia seja salvaguardado, visto que esta, enquanto resultado de uma atividade pessoal e historicamente determinada, não ignora seu compromisso com a manifestação da verdade e do ser.

Todavia, o autor admite que possa haver uma colaboração entre filosofia e senso comum, tendo em vista que, ao colocar o problema da experiência, a filosofia traz para o interior de seu discurso problemas presentes no senso comum. Em Estética: teoria da formatividade Pareyson nos esclarece que é inerente ao pensamento filosófico ser uma reflexão que nasce através do contato a experiência. A partir dela, a filosofia poderia fornecer-nos 
esquemas para interpretá-la e critérios para avaliá-la. Por outro lado, este apelo à experiência concreta pode ser justificado, também, pelo fato de que a relação ontológica originária, ao assegurar a identidade de teoria e práxis, certifica a presença do ser na base de toda atividade humana.

Concluo afirmando que a tradução realizada por Maria Helena Nery Garcez e Sandra Neves Abdo vem ratificar o fato de que o conhecimento do assunto é indispensável para a qualidade do texto. Em especial, gostaria de manifestar o devido reconhecimento ao trabalho realizado pela Profa. Sandra Neves Abdo e seu esforço na divulgação do pensamento pareysoniano, ao qual dedicou grande parte de sua vida acadêmica. Esta aguda frequentação da filosofia de Luigi Pareyson, por parte das tradutoras, permitiu que o texto brasileiro pudesse conservar a mesma precisão de idéias do original em italiano e o mesmo estilo desenvolvido pelo autor, seja pela consideração dos neologismos criados por ele, que foram conservados nesta edição da Martins Fontes, seja pela não intervenção na sua lógica discursiva, aspectos estes que garantem a elegância de sua expressão. Consentindo, assim, que a tradução brasileira estivesse à altura do original italiano e não se tornasse, como é comum acontecer com algumas traduções, uma via tortuosa ao pensamento deste brilhante pensador. 